\title{
HISTOPATHOLOGICAL AND ULTRASTRUCTURE FEATURES OF HYDATID CYST FROM SLAUGHTERED ANIMALS IN EGYPT
}

By

\author{
ABD ALLAH A. A. AL HOOT, HESHAM M. SHARAF*, AMIRA I. EL-KABBANY \\ AND SHIMAA S. HASSAN \\ Department of Zoology, Faculty of Science, Zagazig University \\ ( ${ }^{*}$ Correspondence: sharaf_hesham@yahoo.com)

\section{Abstract}

In the current study, the hydatid cyst-induced tissue lesions in liver and lung of camels and sheep infected with Egyptian strain of E. granulosus was evaluated and the fine structures of the protoscolices by scanning electron microscope (SEM) was described. The results indicated that both fertile and sterile hydatid cysts could lead to various degree of tissue lesions visualized mainly as necrosis, inflammatory cell infiltration and tissue degeneration other histopathological changes occurred in lung and liver of infected animals due to infection with hydatid cyst. Tissue lesion associated with hydatidosis was described. SEM showed envaginated, invaginated protoscolex and the broad capsule of hydatid cyst. There were two types of hooks, large (upper row) and small (lower row) in hydatid cyst protoscolices; with microtriches on different regions.

Keywords: Hydatidosis, SEM, Microtriches, Evaginated \& invaginated, Protoscolex

\section{Introduction}

Generally, the echinococcosis/hydatidosis are of world distribution (Eckert and Thom-pson, 2017). Echinococcal disease is caused by infection with the metacestode stage of the tapeworm Echinococcus, of family Taeniidae (Jenkins et al, 2005). Four Echinococcus species produce infection in humans; E. granulosus and E. multilocularis are the most common, causing cystic echinococcosis (CE) and alveolar echinococcosis (AE), respectively. The two other species, E. vogeli and E. oligarthrus, cause polycystic echinococcosis but only rarely have been associated with human infection (Xiao et al, 2006). The life cycle of Echinococcus involves a definitive and an intermediate host. Humans are accidental hosts and do not play a role in the biological cycle. The different Echinococcus species have different geographic distributions and involve different hosts. Even within a species, different strains infect different animals and vary in their morphology, genetic characteristics, infectivity to humans, and pathogenicity (Eckert and Thompson, 1997). Echinococcus granulosus consists of a complex of three species and eight defined strains, based on morphology, host specificity and molecular characteristics (Schantz, 1999). Taxonomy of Echinococcus is now undergoing changes to reflect these strain variations, and $E$. granulosus may be split into several distinct species (Romig et al, 2006). The risk factors accounted for hydatidosis could be influenced by environmental variability and change through effects on the parasites, animal intermediate and definitive hosts, and human populations (Cadavid Restrepo et al, 2018).

In Egypt, zoonotic hydatidosis was encountered in man (Mazyad et al, 1998), edible animals such as camels, sheep and cattle (Haridy et al, 2000; 2006), and in the definitive host, street dogs in urban and rural areas (Elshazly et al, 2007). Barghash et al. (2017) stated that E. granulosus, hosted by humans and animals, impose serious human health risk and cause significant livestock production loss and widely seen endemically in the Middle East countries. They reported that in Egypt different rates of animals' infection, with an overall hydatidosis prevalence, was (1137/ 7870 or $14.4 \%$ ). The highest incidence of infection was in sheep (331/ 1355 or $24.4 \%$ ) followed by goats (256/ 1322 or $19.4 \%)$, pigs $(26 / 137$ or $18.9 \%)$, camels $(414 / 2212$ or $18.7 \%)$, and donkeys (70/503 or $13.9 \%)$.

Undoubtedly, SEM has provided valuable information on the structure of the protoscolices, which are the infective stage for the canine host (Elmajdoub and Rahman, 2015). 
The current study aimed to describe the extent of tissue lesions caused by hydatid cysts in lung and liver of Egyptian Camels and Sheep collected from three governmental abattoirs and to compare tissue damage caused by sterile and fertile cysts as well as protoscolices evagination process and their morphometric features.

\section{Materials and Methods}

The present study was conducted in three abattoirs; two abattoirs in Sharkia Governorate (Zagazig the Capital and Belbis City) and one in Cairo Governorate (El-Basateen abattoir) during the period from February 2016 to March 2017. The animals studied were sheep (Ovise aries), camels (Camelus dromedarius), cows (Bos taurus) and buffaloes (Bubalus bubalis). The animals at the slaughtering time were macroscopically examined sometimes added by hand lens and palpation of internal organs for the presence of hydatid cyst. The examined organs were lung, liver, spleen, kidney, lymph nodes, heart, tongue, muscles and body cavity. In positive cases, the site and number of cysts were recorded in each animal species.

Infected organs for hydatid cyst were collected in plastic bags for further laboratory examination. The infected visceral organs were separated from the carcass to note the size and number of hydatid cysts present. Intact hydatid cysts recovered from the animals were placed separately in the polythene bags containing ice for further laboratory examination.

Hydatid cysts were excised from the organs, preserved in normal saline solution $(0.7 \%)$ till examined. To examine the internal structures of the hydatid cysts, the external cyst wall was firstly sterilized with ethanol. Then, the cyst wall was penetrated by a needle and the wall was excised by a sterile scissor and the contained fluid was evacuated in a sterile volume graded container. The cyst germinal layers were carefully detached from the cyst wall and were kept in normal saline solution $(0.7 \%)$ till examined. The collected hydatid fluid was centrifuged at
1500 round per minute (rpm) for $5 \mathrm{~min}$. The supernatant was discarded and the sediment materials were examined. For histopathological examinations pieces of infected organs were fixed in $10 \%$ formalin for $24 \mathrm{hrs,} \mathrm{em-}$ bedded in paraffin, cut in serial sections, stained with hematoxlyin and eosin, and examined (Garcia and Bruckner, 1997).

SEM examinations (Galindo et al, 2008): Protoscolices were collected from randomly selected hepatic and pulmonary cysts were washed three times in phosphate buffer saline (PBS), fixed in 3\% (V/V) glutaraldehyde for 24 hours, then washed in $0.1 \mathrm{M}$ PBS. The samples were then centrifuged twice at $1500 \mathrm{rpm}$ for $5 \mathrm{~min}$. The supernatant was discarded, and the pellets were suspended in $1 \%(\mathrm{~V} / \mathrm{V})$ Osmium tetraoxide (OsO4) prepared at room temperature. Then, the samples were dehydrated in ethanol and acetone, dried in a Polaron E 3000 apparatus at the critical point for 1 hour. The specimens were then secured onto aluminium stubs using aluminium tape and final goldcoated in a Samsputter-2a automatic sputtercoating apparatus. The materials were visualized under JEOL JSM 6510 lv. Japan.

\section{Results}

Hydatid cysts were present in lung and liver of infected camels as single or multiple ones located beneath each other. Liver was frequently showed multiple cysts compared to lung, which were more or less sterile (Fig. 4). On evacuating the cysts fluid, the cysts wall became shrinked and the germinal membrane was detached from the inner cyst wall (Fig. 3). Upon examination, hydatid cysts were detected in camels' lung (Figs. 1, 2\&4) and liver (Fig. 4). Other hydatid cysts were embedded underneath organ surface in the parenchyma, identified by hand palpation (Figs. 1, 4). Both dorsal and ventral aspects of the examined organs were affected, other hydatid cysts were found in the heart of infected sheep (Fig. 5).

The highest number of hydatid cysts was in animals slaughtered at Belbis Abattoir, followed by El-Basateen Abattoir and the 
least number was in Zagazig Abattoir. In camels and sheep, the majority of the cysts were found in (91\%) lung followed by $(7 \%)$ liver and least was (2\%) in heart (Fig. 6). The highest number of hydatid cysts was in camels $(n=56)$ followed by sheep $(n=11)$, but none was identified in cows or buffaloes. Evaginated and invaginated protoscolices were observed attached with germinal layer of fertile pulmonary hydatid cyst (Fig. 8).

Histopathological analyses of hydatid cysts gave information about hydatid cyst structure. After detachment of the germinal layer, the inner cysts wall consisted of striated hyalinized eosinophilic layer (laminated layer) that do not contain epithelial cells (Fig. 9). Some of the hydatid cysts had a thickened wall (Fig. 2), in which cysts, the laminated layer appeared thicker than normal (Fig. 9). The remnants of the germinal layer were attached to the laminated layer (Fig. 10). In the fertile hydatid cysts, several eosinophilic protoscolices were found adherent to the germinal membrane or scattered in the lung parenchyma (Fig. 12). The germinal layer appeared as thin granular deep eosinophilic cellular membrane with free protoscolices attached to it with a laminated layer in some of them (Fig. 10).

The fertile hydatid cysts in lung were characterized by the presence of the parasitic germinal layer. The laminated layer had variable staining affinity; some layers were pale esinophilic stained and others were pale basophilic (Fig. 13). The lung alveolar lumen and interstitial tissue contained degenerated and non-degenerated protoscolices (Figs. 14\&15). The adjacent lung parenchyma was distorted, collapsed, infiltrated by mononuclear cells and the pulmonary epithelium was atrophied (Fig. 15). Interestingly, some pulmonary blood vessels contained single protoscolex with damage of the vascular endothelium at the vicinity of parasitic element (Fig. 16). Thickened fibrous layer and sever necrosis with eosinophilia and scattered inflammatory cells with fibrous tissue, after these layer, pulmonary tissue appears as de- generated fibrous tissue with foci of inflammatory cells (Fig.15\&16).

The sterile hydatid cysts were identified in pulmonary (Fig. 17) and hepatic tissues (Fig. 20). Cyst wall retained the normal structure, but neither germinal membrane nor protoscolices attached to or embedded in the tissue parenchyma (Figs. 17-20). In infected lung, sterile cysts induced various degrees of chronic bronchitis, alveolar collapse and intense inflammatory cells infiltrations (Fig. 17). Other parts of the lung revealed congestion and emphysema (Fig. 17). In liver, the sterile cysts appeared as degenerated cysts replacing the liver tissue. The adjacent hepatic parenchyma revealed intense inflammatory reaction and steatosis (Figs. 19\&20) Lymphatic vessels appeared dilated and intense inflammatory reaction is observed consisted mainly of lymphocytes (Figs. $19 \&$ 20). Atrophied hepatic tissues were seen in-between the highly proliferated fibrous tissues (Fig. 19).

SEM (Figs. 21-26), enabled visualization of maturation stages of protoscolices starting from the immature invaginated ones ending with the fully mature evaginated protoscolices. The invaginated protoscolex appeared as small round to oval structure covered by corrugated and shrinked tegument and the origin of rostellar region appeared as a hallo on the anterior part of the invaginated protoscolices (Fig. 22). This structure could be also observed in the mature evaginated protoscolex (Fig. 24). At early stage of evagination process, the stalk was not prominent, which was also seen in light miscopy images recorded at the same stage (Figs. 7, 8). However, the stalk became obvious in fully mature evaginated protoscolex (Fig. 24). The present SEM analysis demonstrated that protoscolices collected from lung and liver hydatid cysts held similar structure. Various morphometric features of the mature protoscolices which isolated from lung and liver of infected camels by SEM (Lung length: 108.49 \pm 0.2 width: $59.08 \pm 0.3$, and Liver length: $134.46 \pm 0.4$, width: $68.19 \pm 0.45$ ). 
The rostellar region, sucker region, neck region and body region (Figs. 24, 26). The rostellar region contains the rostellar cone, hooks, rostellar base (Figs. 27, 28). Sucker region with length 15.9-26.8 in Lung and 12.9-20.7 in the liver; formed of 4-suckers (Figs. 24, 25 \& 26). Neck region lied underneath the rostellar base (Fig. 24). Body region represents the remaining part of the protoscolex containing the stalk region at the protoscolex most caudal part. Tegument of the evaginated protoscolices appeared corrugated (Fig. 24). The sucker region was covered with microtriches (Fig. 33), whereas body area without microtriches (Fig. 33). In some cases, hooks were detached from the protoscolices and one of them appear attached to the tegument of protoscolex (Fig. 22).

In the current study, viewing the hook area closely revealed two types of hooks: upper row (long hooks) and low row (short hooks) as (Figs. $27 \& 28$ ). It was not possible to analyze each hook type separately due to the low number of identified hooks. As shown in (Fig. 28) the area of attachment of upper and lower hooks appeared to be empty and showed a hallo shape. Various morphometric measurements of hooks were ob-

\section{Discussion}

The current study showed the presence of hydatid cysts in slaughtered sheep and camels in Zagazig, El-Basateen and Belbis abattoirs. The low incidence of hydatidosis in Zagazig Abattoir might be attributed to the fact that pet-dogs are not an accepted habit as it is in Cairo (Haridy et al, 2008a). In Egypt, hydatidosis was reported in man and edible animals in Assuit and Aswan Governorates (Dyab et al, 2005). Also, hydatid cysts in slaughtered animals were reported as Toukh abattoir (Qalyubia) by Abdel-Aziz and El-Meghanawy (2016), ElBasateen abattoir (Cairo) by Ameret al. (2015), El-Marg and Al-Salam abattoirs by Abdel Aaty et al. (2012), El-Mansoura Abattoir (Dakahlia) by Abbas (2016), Zagazig and Belbis abattoir (Sharkia) by Gab-Allah served under SEM, each hook $(25.892 \pm 0.4)$ consisted of a blade (13.293 \pm 0.44$)$, guard and a handle (12.312 \pm 0.78$)$ (Fig. 29).

The hook handle originates from the rostellum. The hook blade bent toward the rostellar base. The hook guard is important for the hook to be inserted in the rostellar region. An edge was observed between the handle and the guard (Figs. 29\& 30). Another notch is seen on the other side of the guard, at which the hook blade bent toward the rostellar base (Fig. 29), we could identify microtriches on suckers, rostellar base and on the body of protoscolex close to the sucker (Figs. $31 \& 33$ ). Besides, the density and length of microtriches differed on their distribution. The microtriches on the rostellar base measured from 1.3 to1.6 underneath the hooks appeared as spine-like structures and these structures were loosely distributed on the tegument with their ends appeared untangled (Figs. $31 \& 32$ ). The microtriches on the sucker area were appeared as long (0.79-1.119), filament-like threads of high density and their tips tangled together (Fig. 33). In addition to, the microtriches on the body region seemed to be like the ones on the rostellar area, and there was area where no microtriches were visualized (Fig.33) and Saba (2010) as well as Upper Egypt (Dairout and Malawy abattoirs) by Barghash et al. (2017). Hydatidosis were reported in slauightered donkeys in Giza Zoo (Haridy et al, 2008b).

In the present study, buffaloes slaughtered in El-Basateen abattoir were free from hydatid cysts, But, Haridy et al. (2000) and Amer et al. (2015) showed that the presence of hydatid cysts was in low percentage in buffaloes and cows. This difference might be due to the less number of buffaloes examined in the present study and or seasonal infection. Hydatid cysts might be seen in various organs in the infected animal host. However, lung has been shown to be the most common predilection site. In the present study, 91\% of all hydatid cysts were collected from lungs of slaughtered animals. The agreed 
with Gab-Allah and Saba (2010) who revealed similar high percentages of hydatid cyst infection in the animal's lung as compared to the other body organs.

In the current results, the histopathological studies showed the gross pathology of unusual features of hydatid cysts. For instance, some of the collected cysts had an abnormal thick wall, which, in tissue sections, was found to be eosinophilic hyalinized fibrous tissue of the host origin. Tissue lesion associated with hydatidosis has been the subject of many studies (Borai et al, 2013; Elgaili and Gameel, 2014; Mohammed and Osman, 2016; Beigh et al, 2017; Kinkar et al, 2018). In the current study, both fertile and sterile hydatid cysts induced similar pathological alteration at the tissue level irrespective of the organ involved. The current results as well as those shown in the study of Beigh et al. (2017) indicated that the presence of free floating protoscolices and/or germinal membrane with attached protoscolices are the hallmarks of fertile cysts that are infectious for the final hosts.

If the hydatid cysts were exposed to external pressure, they might rupture and releases protoscolices via body fluids. In these cases, protoscolices might lodge in the lumen of pulmonary blood vessel. These current results were hand by hand with (Mohammed and Osman, 2016) who reported that protoscolex was observed in the lumen of hepatic central vein of infected sheep. But, Rogan et al (2006) reported that hydatid cysts might be formed in tissues other than the primary sites, due to the migration of protoscolices via blood stream, particularly knowing that protoscolices are among the stages that might give rise to new hydatid cysts.

On the contrary, to fertile cysts, the sterile cysts typically lack protoscolices or fluid, leaving the tissue with only anti-cyst inflammatory reaction and degeneration. Regarding the nature of the tissue lesion, the investigated results coincided with those mentioned previously (Borai et al, 2013; Elgaili and Gameel, 2014; Beigh et al, 2017).

In the present study, the lungs showed necrosis, hyaline degeneration and thinning of inter-lobular septa but, this obtained result seemed to be conceivable with Beigh et al (2017). On the other hand, in the infected liver, atrophied hepatic tissues, congestion and various degenerative changes were reported, which went with Kinkar et al (2018). In both organs (lung and liver), there was inflammatory cell scattered or clustered adjacent to the cysts wall.

In the most necrotic area, the laminated layers could not be collected together with adherent liver or lung tissue and the adventitial layer appeared completely degenerated and it replaced by degenerated inflammatory cells, and these results were in fully agreement with (Borai et al, 2013; Beigh et al, 2017; Kinkar et al, 2018).

In the present study, the SEM visualized the fine details of immature (invaginated) and mature (evaginated) protoscolices. The structure of invaginated protoscolices corporates was in previous reports (Warren et al, 1995; Elmajdoub et al, 2014), particularly their corrugated surface and the oval shape.

In the present study, also the morphological features (length \& width) of the mature evaginated protoscolices collected from lung and liver hydatid cysts of camels proved that they were of the typical E. granulosus strain. The hook morphology and metrics proved to be a useful tool for taxonomic identification of Echinococcus spp. (Warren et al, 1995; Almeida et al, 2009; Elmajdoub et al, 2014).

In the current results showed two types of hooks in hydatid cyst protoscolices based on morphometric characteristics: large (upper row) and small (lower row) hooks. This agreed with Antoniou and Tselentis (1993) and Elmajdoub et al. (2014). Besides, third type (smaller hooks) was in the rare cases as reported by Smith and Richards (1991). They reported that the handle length of the large and small hooks was smaller than that in this study. In the present study, hooks 
were arranged in two rows, with the larger ones arranged in upper row and the smaller hooks in the lower row, all the hooks were fully mature without any identification of a third hook type "very small" as described by Smith and Richards (1991). Generally, the current results and others reported the importance of the hook measurements as a tool to identify the etiology of hydatid cyst.

The present results showed at least two types of microtriches on the protoscolices, the one on the rostellar base was less dense and shorter than that on the sucker area. The agreed with Thompson et al. (1982) who identified microtriches on other places on $E$. granulosus adult such as strobili and on the apical portion of rostellum, indicating that microtriches distribution and intensity might differ in adult stage. On the other hand, Antoniou and Tselentis (1993) reported that there were some areas of the sucker microtriches were left bare without microtriches. The presence of microtriches in the investigated study and in other studies suggested that they play important role in sensing the chemical stimuli in the environment.

In Egyptian patients, so many authors reported zoonotic hydatidosis in liver (Abdel aal and Dabbous, 2014), lung (Aldahmashi et al, 2016), brain (Abdel Razek et al, 2009), bone marrow (Mazyad et al, 1999) and kidney (Gadelkareem et al, 2018)

\section{Conclusion}

Undoubtedly, hydatidosis in man and animals is a real risky public health and economic problem not only in Egypt but also in many countries worldwide. Periodical examination and de-worming at least of pet-dogs must be in mind as well as sanitary deposit of the wastes and garbage.

The control of stray (street) dogs must be considered by the Public Health, Agricultural and Veterinary-Medical Authorities. Also, the bad habit of slaughtering outside the official slaughterhouses under the hygienic rules must be prohibited.

Conflict of Interest: Authors declared that they neither have interest nor received fund.

\section{Acknowledgment}

The authors would like to thanks the Veterinary-Medical Authorities in the Official Abattoirs of Zagazig and Cairo for facilitating this field work.

\section{References}

Abbas, I, 2016: Molecular and epidemiological updates on cystic echinococcosis infecting water buffaloes from Egypt. Vet. World 9:1355-63.

Abdelaal, AM, Dabbous, IH, 2014: Hydatid disease of the liver: laparoscopic approach, initial result in Egypt. J. Egypt. Soc. Parasitol. 44, 3: 619-25.

Abdel-Aaty, HE, Abdel-Hameed, DM, AlamEldin, YH, El-Shennawy, SF, Aminou, HA, et al, 2012: Molecular genotyping of Echinococcus granulosus in animal and human isolates from Egypt. Acta Trop. 121:125-8.

Abdel-Aziz, AR, El-Meghanawy, RA, 2016: Molecular characterization of hydatid cyst from Egyptian one humped Camels (Camelus dromedaries). PSM Vet. Res. 1:13-6.

Abdel Razek, AA, El-Shamam, O, Abdel Wahab, N, 2009: Magnetic resonance appearance of cerebral cystic echinococcosis: WHO classification. Acta Radiol. 50, 5:549-54

Aldahmashi, M, Alassal, M, Kasb, I, Elrakhawy, H, 2016: Conservative surgical management for pulmonary hydatid cyst: Analysis \& outcome of 148 cases. Can. Respir. J. 2016:8473070

Almeida, BF, Rodrigues-Silva, R, Neves, HR, Gonçalves, MML, Romani, ELS, et al, 2009: Morphological and morphometric studies on protoscoleces rostellar hooks of Echinococcus granulosus from Peru visualized by several microscopic techniques. Neotrop. Helminthol. 3:6572.

Amer, S, Helal, IB, Kamau, E, Feng, Y, Xiao, L, 2015: Molecular characterization of Echinococcus granulosus sensu lato from farm animals in Egypt. PLoS One. 10:e0118509.

Antoniou, M, Tselentis, Y, 1993: Studies on Echinococcus granulosus using the scanning electron microscope. I. Preparations of the parasite for infection of the final host. Parasitol. Res. 79:537-42.

Barghash, SM, El Sayed, RA, El-Alfy, NM, Abou-Elnour, BM, El-Kattan, AM, et al, 2017: Prevalence and molecular identification of Echinococcus granulosus in humans and slaughtered animals in Egypt. Euro. J. Biomed. Pharma Sci. 4, 9:34-42. 
Beigh, AB, Darzi, MM, Bashir, S, Kashani, B, Shah, A, Shah, SA, 2017: Gross and histopathological alterations associated with cystic echinococcosis in small ruminants. J. Parasit. Dis. 41:1028-33.

Borai, MGE, Nagi, AA, Gab-Allah, MS, ElMashad, AI, Moustafa, SA, 2013: Comparative pathological studies on parasitic affections of liver in farm animals. Benha Vet. Med. J. 25: 284-95.

Cadavid Restrepo, AM, Yang, YR, McManus, DP, Gray, DJ, Barnes, TS' et al, 2018: Spatiotemporal patterns and environmental drivers of human echinococcoses over a twenty-year period in Ningxia Hui Autonomous Region, China. Parasit. Vectors Feb 22;11(1):108. doi: 10.1186/ s13071-018-2693-z.

Dyab, KA, Hassanein, R, Hussein, AA, Metwally, SE, Gaad, HM, 2005: Hydatidosis among man and animals in Assiut and Aswan Governorates. J. Egypt. Soc. Parasitol. 35, 1:157-66.

Eckert, J, Thompson, RC, 1997: Intraspecific variation of Echinococcus granulosus and related species with emphasis on their infectivity to humans. Acta Trop. 64:19-24.

Eckert, J, Thompson, RC, 2017: Historical aspects of echinococcosis. Adv. Parasitol. 95:1-64

Elgaili, S, Gameel, A, 2014: Pathological, histochemical and immunohistochemical studies of lungs and livers of cattle and sheep infected with hydatid disease. $5^{\text {th }}$ Ann. Conf. Agric. Vet. Res., Khartoum, Sudan.

Elmajdoub, LO, Rahman, WA, 2015: Preva lence of hydatid cysts in slaughtered animals from different areas of Libya. Open J. Vet. Med. 5:1-10.

Elmajdoub, LO, Rahman, WA, Fadzil, M, Mohd, SA, 2014: Studies on the protoscoleces and hooks of Echinococcus granulosus from Libya by scanning electron microscope. Acta Med. Inter. 1:74-81.

Elshazly, AM, Awad, SE, Abdel Tawab, AH, Haridy, FM, Morsy, TA, 2007: Echinococcosis (zoonotic hydatidosis) in street dogs in urban and rural areas, Dakahlia Governorate, Egypt. J. Egypt. Soc. Parasitol. 37, 1:287-98.

Gab-Allah, HM, Saba, SER, 2010: Incidence of hydatid cysts in slaughtered animals and their relation to public health at Sharkia Province. Egypt. J. Agric. Res. 88:285-90.

Gadelkareem, RA, Elqady, AA, Abd-Elshafy, SK, Imam, H, Abolella, HA, 2018: Isolated renal hydatid cyst misdiagnosed and operated as a cystic renal tumor. Med. Princ. Pract. 27, 3: 297-300.

Galindo, M, Schadebrodt, G, Galanti, N, 2008: Echinococcus granulosus: cellular territories and morphological regions in mature protoscoleces. Exp. Parasitol. 119:524-33.

Garcia, LS, Bruckner, DA, 1997: Diagnostic Medical Parasitology, $3^{\text {rd }}$ Edition, ASM Press Washing-ton DC, USA.

Haridy, FM, Ibrahim, BB, Morsy, TA, 2000: Sheep-dog-man: The risk zoonotic cycle in hydatidosis. J. Egypt. Soc. Parasitol. 30:423-9.

Haridy, FM, Ibrahim, BB, Elshazly, AM, Awad, SE, Sultan, DM, El-Sherbini, GT, Morsy, TA, 2006: Hydatidosis granulosus in Egyptian slaughtered animals in the years 2000-2005. J. Egypt. Soc. Parasitol. 36:1087-100.

Haridy, FM, Holw, SA, Hassan, AA, Morsy, T A, 2008a: Cystic hydatidosis: a zoonotic silent health problem. J. Egypt. Soc. Parasitol. 38, 2:635-44.

Haridy, FM, Abdel Gawad, AG, Ibrahim, BB, Hassan, AA, El-Sherbi, GT, et al, 2008b: Zoonotic hydatidosis in donkeys: post-mortum examination in the Zoo, Giza, Egypt. J. Egypt. Soc. Parasitol. 38, 1:305-12.

Jenkins, DJ, Romig, T, Thompson, RC, 2005: Emergence/re-emergence of Echinococcus spp.a global update. Int. J. Parasitol. 35:1205-9.

Kinkar, L, Laurimäe, T, Acosta-Jamett, G, Andresiuk, V, Balkaya, I, et al, 2018: Global phylogeography and genetic diversity of the zoonotic tapeworm Echinococcus granulosus sensu stricto genotype G1. Int. J. Parasitol. 48:729-42.

Mazyad, MA, Mostafa, MM, Morsy, TA, 1998: Spinal cord hydatid cysts in Egypt. J. Egypt. Soc. Parasitol. 28, 3:655-8.

Mazyad, MA, Morsy, TA, Habib, KS, 1999: Vertebral unilocular hydatidosis in a shepherd \& his wife. J. Egypt. Soc. Parasitol. 29, 2:547-50.

Mohammed, NH, Osman, HM, 2016: Histopathological Studies on Liver Affected with Hydatidosis in one Humped Camel (Camelus dromedarius) in Tampool Slaughterhouse, Sudan. Ann. Res. Rev. Biol.11:1-6.

Rogan, MT, Hai, WY, Richardson, R, Zeyhle, E, Craig, PS, 2006: Hydatid cysts: does every picture tell a story? Trends Parasitol. 22:431-8.

Romig, T, Dinkel, A, Mackenstedt, U, 2006: The present situation of echinococcosis in Europe. Parasitol. Int. 55, 1:S187-92.

Salih, M, Degefu, H, Yohannes, M, 2011: Infection rates, cyst fertility and larval viability of 
hydatid disease in camels (Camelus dromedari$u s$ ) from Borena, Kereyu and Harar Areas of Ethiopia. Glob. Vet. 7:518-22.

Schantz, P, 1999: Echinococcosis. In: Tropical Infectious Diseases: Principles, Pathogens and Practice. $1^{\text {st }}$ Edi, by Guerrant, R, Walker, DH, Weller, PF, WB Saunders, Philadelphia, USA.

Smith, SA, Richards, KS, 1991: Ultrastructure and microanalyses of the protoscolex hooks of Echinococcus granulosus. Parasitology 103, Pt 2:267-74.

Thompson, RCA, Houghton, A, Zaman, V,
1982: A study of the microtriches of adult Echinococcus granulosus by scanning electron microscopy. Int. J. Parasitol. 12:579-83.

Warren, BA, Yong, JL, Chauvin, WJ, 1995: The scanning electron microscopy of scolices in a case of hydatid cyst from human liver. Pathology $27: 318-23$.

Xiao, N, Qiu, J, Nakao, M, et al, 2006: Echinococcus shiquicus, a new species from the Qinghai-Tibet plateau region of China: discovery and epidemiological implications. Parasitol. Int. 55, 1:S233-40.

\section{Explanation of figures}

Fig. 1: Fertile Hydatid cysts in lung of infected sheep. Arrows refer to embedded hydatid cyst (HC).

Fig. 2: Protruded sterile hydatid cyst with thickened wall (head arrow) in lung of infected sheep (arrow)

Fig. 3: Germinal membrane (GM) (arrow) after detachment from wall of fertile pulmonary hydatid cyst.

Fig. 4: Sterile hydatid cyst embedded in liver of infected sheep (arrow).

Fig. 5: Heart of sheep (slaughtered in El-basateen abattoir) infected with small-caseated hydatid cyst (arrow). HC; hydatid cyst

Fig. 6: Hydatid cysts percentage from various organs of examined animals (Camel and Sheep).

Fig. 7: Immature invaginated protoscolex from pulmonary hydatid cyst of infected camel showing hooks and stalk origin (arrowhead)

Fig. 8: Mature evaginated protoscolex (white arrow) and invaginated protoscolex (black arrow) from Camel lung. H, hooks; SO, stalk origin; EP, Evaginated protoscolex; IP, Invaginated protoscolex.

Fig.9: Cross section in hydatid cyst wall after removing germinal membrane, cyst cavity (star), laminated layer ( $L L$ ) (arrow) followed by several layers of degenerated hyalinezed fibrous tissue (double head arrow) X400.

Fig.10: Germinal membrane (GM) with free protoscolices (arrowhead) X100

Fig. 11: Laminated layer (double arrowhead) and free invaginated protoscolex (IP) (black arrow) attached to laminated layer (white arrow) $\mathrm{X} 400$.

Fig.12: Detached germinal membrane (black arrow), laminated layer (white arrow) and protoscolices (arrowhead) floating in cyst cavity (star) X200. LL, laminated layer; GM, germinal membran; IP, invaginated protoscolex.

Fig.13: Normal lung tissue X100 ES, eosinophilic stain; BS, basophilic stain

Fig.14: Fertile hydatid cyst in lung tissue of infected Camel pulmonary tissue containing protoscolices (arrow) X100, IP, invaginated protoscolex.

Fig.15: Magnified protoscolices (black arrows) embedded in pulmonary tissue and atrophied pulmonary epithelium (doublehead white arrow) $\mathrm{X} 200$.

Fig.16: Protoscolex (arrow) in blood vessels lumen (star) X400. ES, eosinophilic stain; BS, basophilic stain; VE, vascular endothelium; IP, invaginated protoscolex.

Fig.17: Sterile hydatid cysts in lung showing inner cyst wall (black arrow) followed by a dense layer of hylanized fibrous capsule of host origin (star) and adjacent pulmonary tissue revealed congestion, emphysema and infiltrated with inflammatory cells (white arrows). No protoscolices. X400

Fig. 18: Normal hepatic parenchyma X100.

Fig.19: Atrophied hepatic cords (white arrow) and degenerated hepatic parenchyma with intense inflammatory reaction formed of lymphocytes (arrow) X100.

Fig. 20: Liver tissue infected with sterile hydatid cyst suffers from different degenerative changes (arrow) and infiltration of inflammatory cells X200

Fig.21: SEM of Brood capsules (arrow) collected from pulmonary hydatid cyst collected from infected Camel

Fig.22: SEM of invaginating protoscolex collected from pulmonary hydatid cyst from infected Camel and one of hook (H) was attached to tegument (thin arrow). $\mathrm{H}$, hooks; $\mathrm{RC}$, rostellar cone.

Fig. 23: Mature evaginated protoscolices collected from liver of infected camel.

Fig.24: SEM of mature evaginated protoscolex collected from lung of camel showing hooks $(\mathrm{H})$, suckers(S) and stalk region origin (ST)

Fig.25: SEM of Lateral view of evaginated protoscolex collected from hydatid cyst in lung of camel.

Fig.26: SEM of Lateral view of evaginated protoscolex collected from hydatid cyst in an infected Camel liver. S, sucker; RB: rostellar base; $\mathrm{RC}$, rostellar cone; H: hooks, ST: stalk, NR, neck region.

Fig.27: SEM of rostellar cone with two rows of hooks, upper (long hooks) and lower row (short hooks) isolated from lung of infected Camel. Fig.28: SEM of rostellum with hallo shape showing hooks. H: hooks, RB: rostellar base.

Fig.29: SEM of detailed structure of hook

Fig.30: SEM Measurements of the hook angels using computer image analysis System. H, hooks; RB, rostellar base; RC; rostellar cone; D: Total length, A: blade length, B: handle length and C: hook width.

Fig.31: SEM of Microtriches $(M)$ on rostellar region of protoscolex isolated from liver hydatid cyst.

Fig.32: SEM of high magnification Microtriches on rostellar base (RB) (below hooks) of protoscolex isolated from lung hydatid cyst.

Fig.33: SEM of Microtriches (red arrows) found on sucker region (SR) of a protoscolex isolated from liver hydatid cyst. M, microtriches; S, sucker; H, hook. 


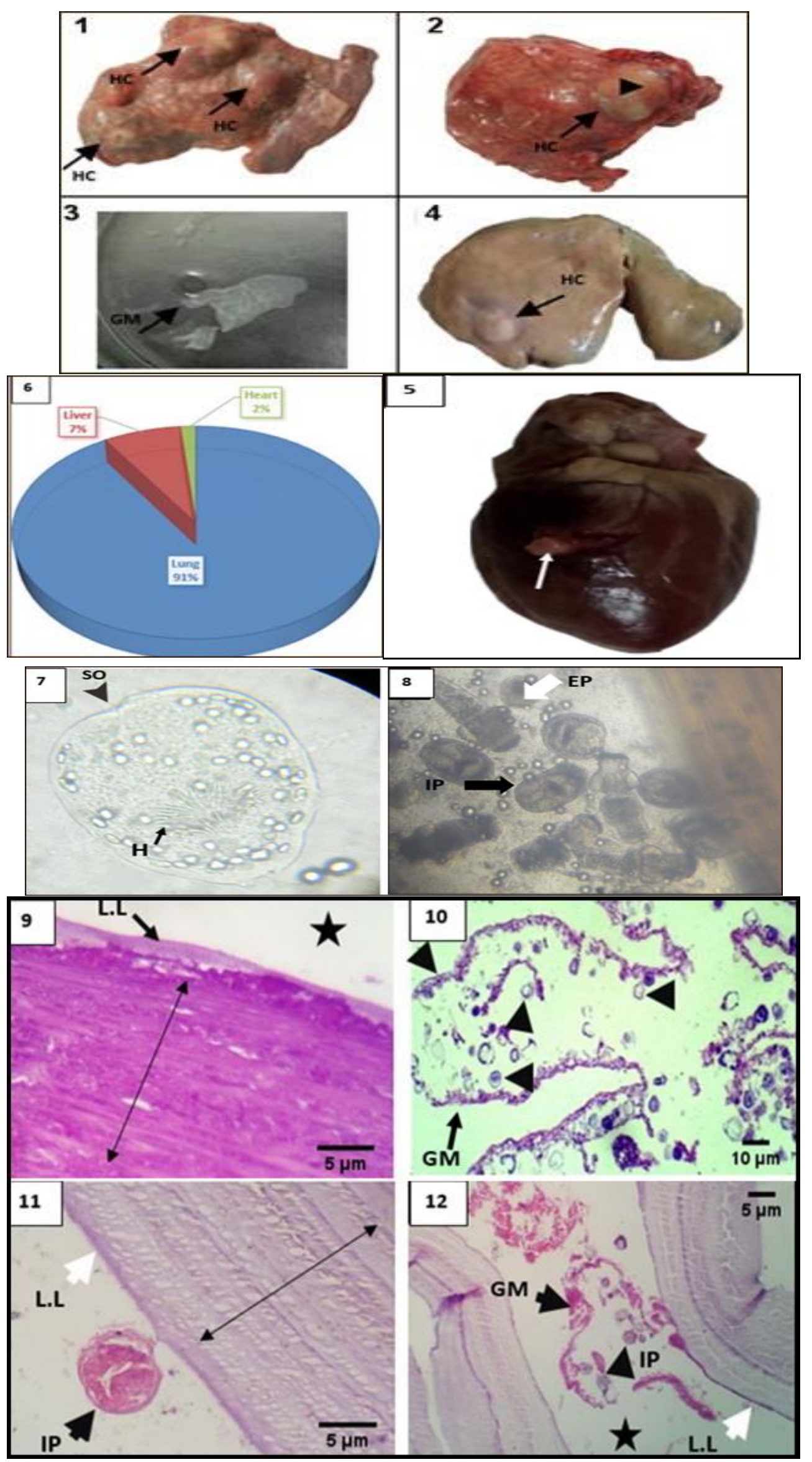



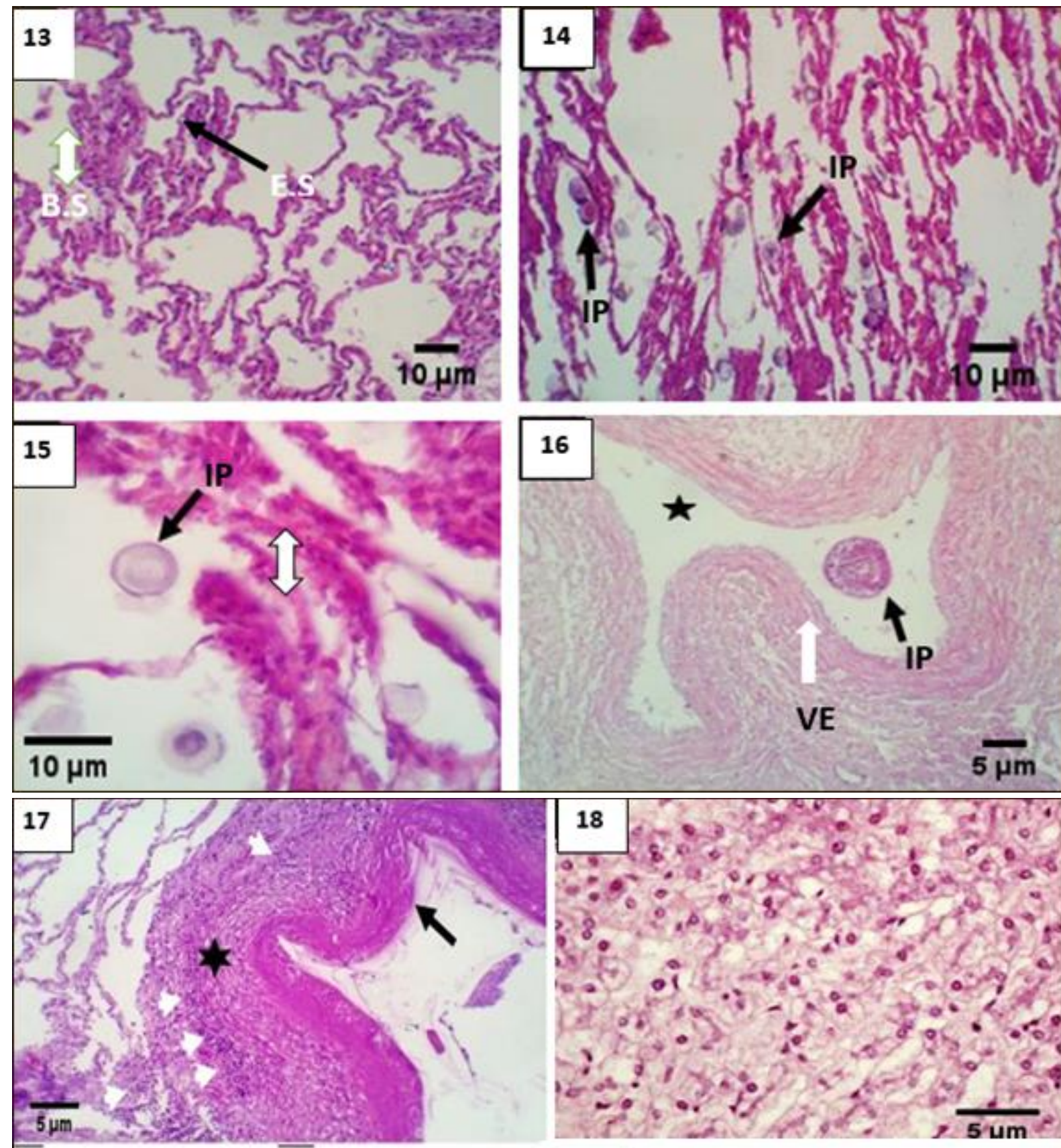

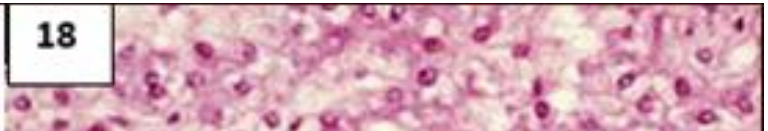

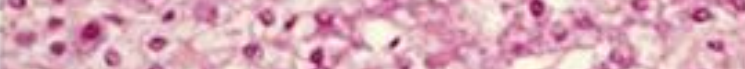
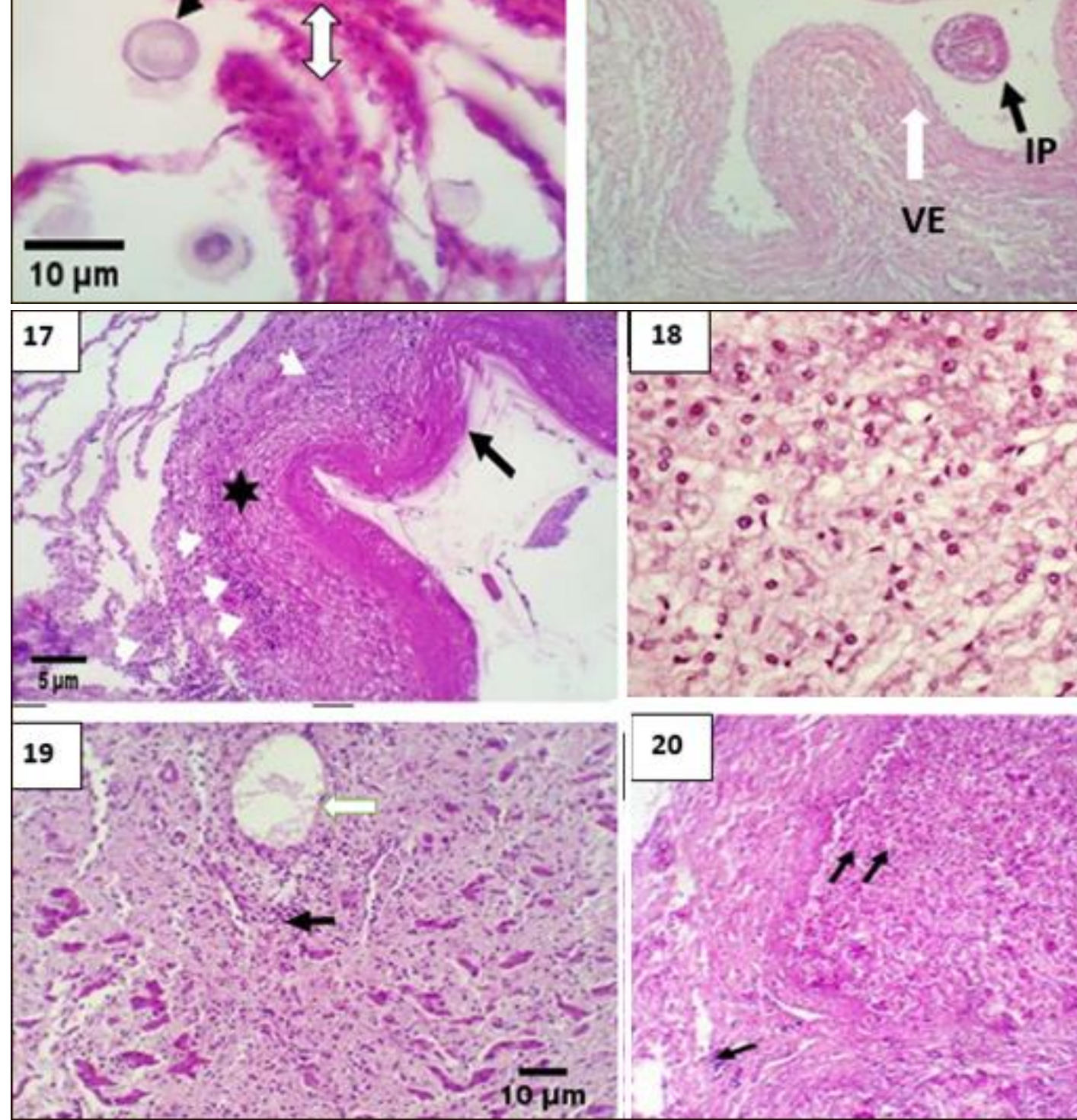

VE

$5 \mu \mathrm{m}$
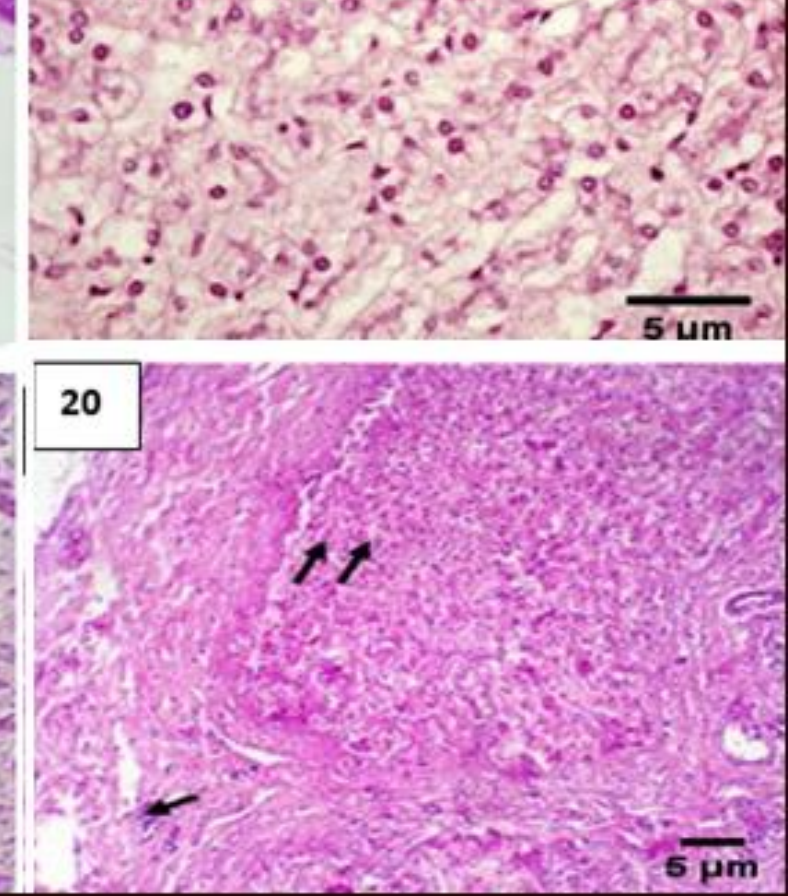

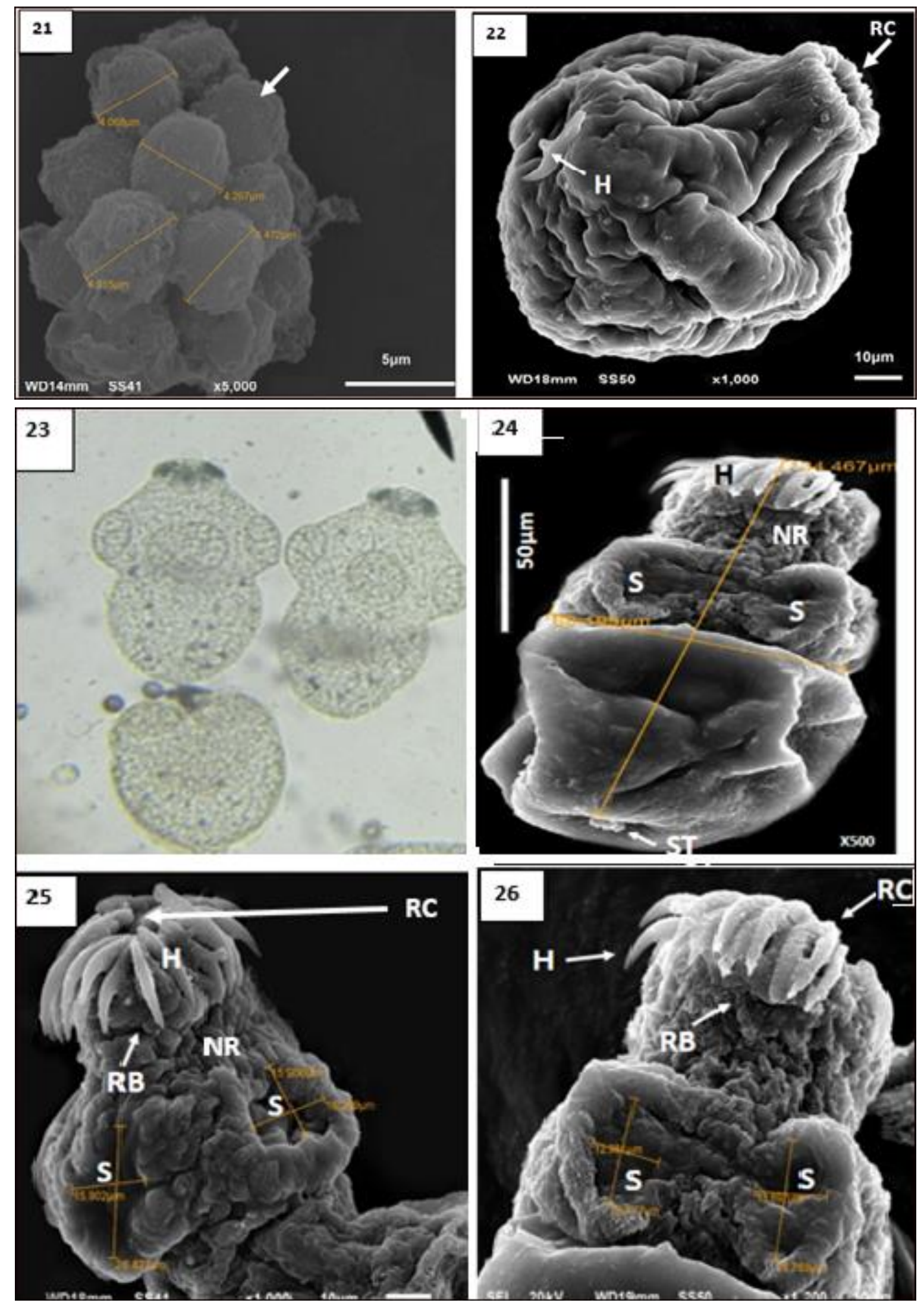

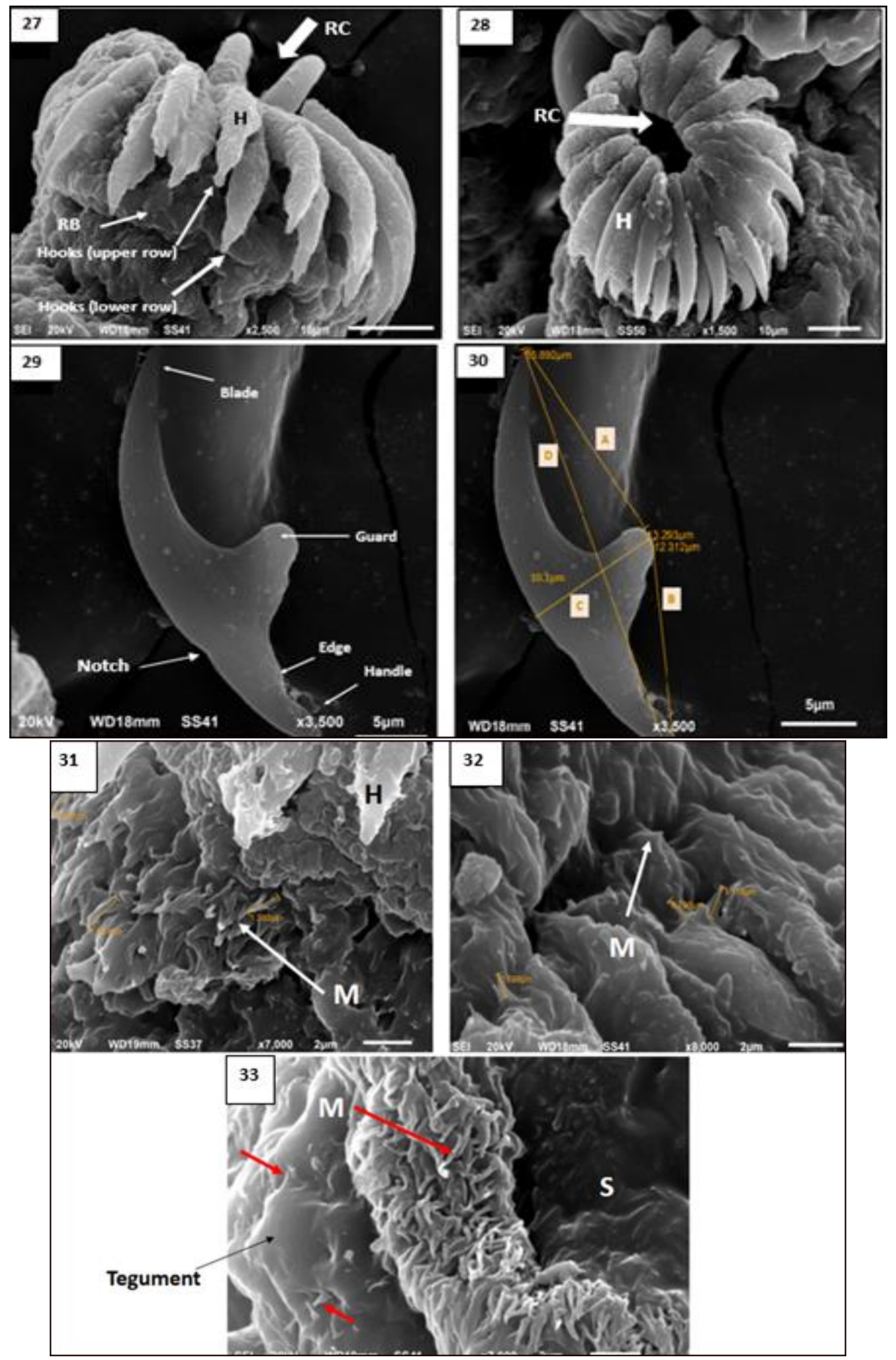